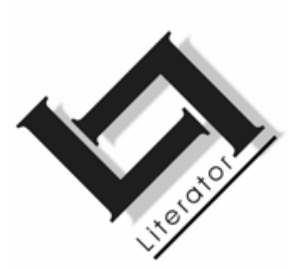

\title{
Spore van migrasie en verlies in Krzysztof Kieślowski se Three colours trilogy'
}

\author{
Adéle Nel \\ Skool vir Tale \\ Vaaldriehoekkampus \\ Noordwes-Universiteit \\ VANDERBIJLPARK \\ E-pos: Adele.Nel@nwu.ac.za
}

\section{Abstract \\ Traces of migration and loss in Krzysztof Kieślowski's Three colours trilogy}

This article will focus on Krzysztof Kieślowski's "Three colours trilogy", technically a French-Polish-Swiss co-production. Kieślowski lived in the West while filming the trilogy and therefore the theme of migration can be linked to the director as well as to the films. Kieślowski's condition, however, is not a condition of exile but rather a state of being betwixt-and-between, a hybrid composed of past and present places (Poland and Western Europe). The transition from one space to another can also be identified as a threshold experience: it is an experience of loss of all that has gone before, of absence of both before and after, of anxiety generated by loss and uncertainty, and of desire, which arises from the lack which arose from these experiences. Kieślowski's personal transition and liminal state bring forth the themes and style of the trilogy. The characters also find themselves in transition between two worlds; they live as émigrés of the imagination, conveying the feeling of being both part and not part of their personal world. Each character, in different ways, tries to cope with the loss: Julie in "Blue", through a threshold fixation, Karol in "White", through wrathful revenge, and Kern in "Red", through the strategy of disavowal.

$1 \quad$ Hierdie artikel is ' $n$ verwerking van 'n referaat gelewer in Oxford, UK. Die onderwerp van die kongres was: "Migrant and diasporic cinema in contemporary Europe." 


\section{Opsomming}

\section{Spore van migrasie en verlies in Krzysztof Kieślowski se Three colours trilogy}

Hierdie artikel fokus op Krzysztof Kieślowski se "Three colours trilogy", tegnies 'n Frans-Pools-Switserse ko-produksie. Tydens die verfilming van die trilogie het Kieślowski in die Weste gewoon en gevolglik kan die tema van migrasie aan die regisseur, sowel as die films geknoop word. Kieślowski se posisie in Europa is egter nie dié van ballingskap, of selfs van volwaardige migrasie nie, maar eerder 'n tussentoestand, op die spanningslyn tussen plekke van die verlede én van die hede, naamlik Pole en Europa. Die oorgang van een ruimte na 'n volgende kan bestempel word as ' $n$ drempelervaring: dit is 'n ervaring van verlies van alles wat voorafgegaan het, van afwesigheid van sowel vantevore as later, van angs wat gegeneer word deur die verlies en onsekerheid en van begeerte, as gevolg van die gemis wat ontstaan het. Kieślowski se persoonlike verplasing en liminale staat het die temas en styl van die trilogie tot gevolg. Die karakters bevind hulself ook in transito tussen twee wêrelde; hulle leef as migrante van die verbeelding, en kommunikeer die gevoel van sowel deel as nie deel wees nie van hulle kultuur. Elkeen probeer op 'n persoonlike manier die ervaring van verlies verwerk: Julie in "Blue" deur 'n drempelfiksasie, Karol in "White" deur woedende wraak en Kern in "Red" deur die strategie van ontkenning.

\section{Inleiding}

Literêre en filmtekste is dikwels nie net gewortel in die tydsgees nie, maar reflekteer ook daardie tydsgees en ooglopende tendense en veranderings in die samelewing. Die grootskaalse beweging van mense oor landsgrense is onder andere so 'n wêreldwye tendens en een van die belangrikste eienskappe sowel as kulturele kragte van ons tyd. Die titel van Castles en Miller (1998) se boek, The age of migration: international population movements in the modern world, reflekteer alreeds dié tydsgees. Avtar Brah (1996:178) onderskryf hierdie opvatting met die stelling dat daar aan die einde van die twintigste eeu en die begin van die 21ste eeu 'n toename in migrasie rondom die aardbol is. Die redes vir hierdie bewegings is talryk, en sluit in persoonlike en akademiese redes, politieke redes (wat gedwonge verskuiwing en ballingskap insluit), religieuse redes, ekonomiese redes (insluitend die kwessie van gasarbeiders) en interverwisselinge as gevolg van koloniale geskiedenis. Migrasie as demografiese fenomeen is egter nie by uitstek 'n kontemporêre verskynsel nie. Peters (1999:17) bring as voorbeeld die begrip balling- 
skap met die tema van mens-in-beweging in verband, en maak die volgende relevante stelling:

Concepts of mobility lie at the heart of the Western canon; otherness wanders through its center. Exile is, perhaps, the central story told in European civilization: the human estate as exile from God, the garden of Eden, the homeland, the womb, or even oneself (sy kursivering).

Hierdie eeue oue en wêreldwye verskynsel word deur Neervoort (2006:9) ook tereg in die breë kader van die menslike tekort, die condition humaine, geplaas. Hy interpreteer die oorkoepelende rede vir migrasie voorts as ' $\mathrm{n}$ vergeefse poging om bo dié menslike tekort uit te styg.

Vanweë die feit dat die ervaring van migrasie so ingrypend in die individu se persoonlike lewe 'n ommekeer bring, sowel as die kulturele, sosiale, ekonomiese en politieke gevolge wat dit inhou, het dit onder andere tot gevolg dat daar 'n hele korpus van tekste, hetsy literêr of filmies oor dié onderwerp die lig gesien het. Dit is dikwels die ervaring aan eie lyf wat die migrant noop om die pen op te neem, of in die geval van rolprente, die regisseur-as-migrant die keuse laat maak om die eie of verbeelde ervarings en leefwyses te verfilm. In die geval van die beeldteks, kan die konsep van immigrasie op twee wyses manifesteer. Enersyds kan dit die tema of onderwerp van die film self wees, en andersyds kan dit die regisseur se eie ervarings by implikasie reflekteer deur middel van die artistieke ekspressie of persoonlike styl.

Die Poolse filmregisseur, Krzysztof Kieślowski, se loopbaan kan ooglopend in twee fases verdeel word. In die eerste fase het hy hoofsaaklik dokumentêre films gemaak wat deur die Poolse regering gesubsidieer (en by implikasie ook gesensureer) is. In 1976 skakel hy met die rolprent, The scar, oor na die sogenaamde speelprent. Hierdie tweede fase word ook deur twee verdere deurslaggewende drempelervarings ${ }^{2}$ gekenmerk. In kollektiewe verband is Pole in April 1998 vir die eerste keer sedert die Tweede Wêreldoorlog polities vry na die eerste demokratiese verkiesing in die land. Kieślowski kon gevolglik vrylik na die Weste migreer ter wille van die finansiële voordele wat ko-produksies gebied het. In hierdie periode verfilm hy Double life of Veronique en Three colours trilogy, tegnies Frans-

2 ' $n$ Drempel is 'n grens wat oorgesteek word om van een ruimte na 'n ander te beweeg, hetsy in letterlike of figuurlike sin. 
Pools-Switserse ko-produksies. Volgens Stok (1995:xxi) kon die oorblyfsels van die grouheid en eentonigheid in sy vaderland, sowel as die steeds kloustrofobiese instellings van die Poolse samelewing, 'n bydraende rol gespeel het tot die "opening" van 'n drempel na 'n nuwe ruimte, en sy gevolglike "ontsnapping" na die vryheid van die Weste. Kieślowski se vennootskap met die Wes-Europese produksies bied naamlik aan hom die geleentheid om outonoom en kreatief onafhanklik films te maak, en terselfdertyd sy persoonlike waardes ten gunste van demokrasie, verdraagsaamheid en waarheid (wat in sy laaste films reflekteer) vreesloos uit te beeld.

As vertrekpunt vir hierdie betoog geld die volgende kwessies: in die eerste plek word enkele teoretiese aspekte van migrasie kortliks in oënskou geneem. In die tweede plek word Krzysztof Kieślowski se Three colours-trilogie binne die raamwerk van migrasie geplaas. Daar sal gefokus word op Kieślowski as (tydelike) migrant-regisseur in Europa, en ondersoek sal ingestel word in watter mate dit die temas, die artistieke ekspressie en persoonlike styl van die trilogie beïnvloed het. Die poëtika van verlies, as uitvloeisel van migrasie, en die wyse waarop dit in die betrokke films manifesteer, is enkele aspekte wat in die derde plek ondersoek word.

\section{2. 'n Teoretiese raamwerk vir konsepte van migrasie}

Volgens die WAT word met die term migrasie die handeling, proses of geval van te migreer bedoel. Migreer word gedefinieer as: "een land, streek of plek verlaat ten einde jou in 'n ander te vestig. $\mathrm{Na}$ ander omstandighede beweeg." Ingebed in hierdie definisie is die konsep van verplasing oor landsgrense heen. Hoewel verplasing en migrasie nie sinonieme is nie, kan hierdie terme vir die doel van hierdie betoog as uitruilbaar gebruik word. Die term migrasie word in 'n algemene sin gebruik om te verwys na 'n verskeidenheid kategorieë van mense wat hulle oorspronklike geboorteland moes verlaat, hetsy deur ' $n$ wilsbesluit of onder dwang, en hulle elders gevestig het waar hulle dan sodanige land aanneem as tuiste (sommige net tydelik), totdat die moontlikheid ontstaan om onder beter omstandighede terug te keer. Tans word die term ook algemeen gebruik as 'n merker vir die identiteit van enige subjek wat die sentrum van sy/haar bestaan moes verlaat, en op die een of ander wyse transnasionaal verplaas is. Benewens geografiese grense impliseer migrasie dus ook die oorsteek van talige, kulturele, godsdienstige, sowel as psigologiese grense. Aansluitend by die konsep van migrasie is die term diaspora, wat op verstrooiing dui en wat deur sommige skrywers by voorkeur gebruik word. 
Verskillende teoretici en skrywers oor die konsep van verplasing karteer die topologie van migrasie op verskillende maniere, en beklemtoon 'n verskeidenheid aspekte as belangrik. Vervolgens word enkele insiggewende standpunte kortliks uitgelig. Chambers (1994) is van mening dat migrasie en verplasing 'n (post)moderne kondisie is. Hy beklemtoon in sy boek Migrancy, culture, identity die feit dat globale geografiese verplasing en migrasie 'n komplekse transformasie tot gevolg het. In ons verstaan van verplasing, marginaliteit en die moderne leefwyse, is hierdie transformasie onlosmaaklik verbind aan die metropolisasie van die aardbol, waar die model van die stad terselfdertyd model word vir die kontemporêre wêreld. Die migrant se ervaring van wortelloos te wees, dat hy/sy hom/haar tussen twee wêrelde bevind, naamlik tussen 'n verlore verlede en 'n nie-geïntegreerde hede, is uiteindelik die mees paslike metafoor van hierdie (post)moderne kondisie. Chambers se argumente impliseer met ander woorde dat migrasie 'n letterlike én metaforiese oorgang in ruimte, sowel as in tyd is. Daar is dus sprake van 'n voortdurende dialektiek tussen plek van herkoms en plek van heenkome, tussen die vermiste oorsprong en nuwe identiteit. In aansluiting hierby kan Rushdie (1991:12) se genuanseerde uitgangspunt aangehaal word:

It may be argued that the past is a country from which we have all emigrated, that its loss is part of our common humanity. Which seems to me self-evidently true; but I suggest that the writer who is out-of-country and even out-of-language may experience this loss in an intensified form. It is made more concrete for him by the physical fact of discontinuity, of his present being in a different place from his past, of his being 'elsewhere'.

Die opvatting van migrasie as metafoor word vervolgens ook deur verskeie teoretici gehuldig. William Safran (1991:94) skryf byvoorbeeld dat die probleem van die verhouding tussen die migrant, gasheerland en geboorteland verby die eng etniese, genetiese en emosionele vlak strek, en eerder op metaforiese vlak gelees behoort te word. Hy gebruik as voorbeeld toegewyde Rooms-Katolieke wat in 'n oorwegend Protestantse land woon. Hierdie persone sien hulself as "religieus verplaastes" en sien Rome as hulle geestelike tuisland. Min of meer dieselfde opvatting word ook deur Kearney (1988) geartikuleer. Hy wys op sy beurt daarop dat dit opvallend is hoeveel hedendaagse lerse skrywers die uitspraak maak dat hulle, ten spyte van die feit dat hulle hul in die moederland bevind, in transito tussen twee wêrelde verkeer, verskeur tussen twee opponerende lojaliteite. Hulle skryf dus as émigrés van die verbeelding, 
en kommunikeer die gevoel van sowel deel as nié deel wees van hulle kultuur nie; van vervreemding van die spesifieke tradisies waartoe hulle behoort, kortom, om in ballingskap te wees binne 'n eie tuiste. Hierdie argument reflekteer ook Hannerz (2000:22) se opvatting oor migrasie. Hy redeneer naamlik dat migrasie nie soseer 'n buitengewoon persoonlike ervaring, teweeggebring deur ewe buitengewone politieke omstandighede is nie, maar sien dit eerder as 'n modus van die verbeelding. Kearney, sowel as Hannerz, se opvattings bied gevolglik 'n bruikbare invalshoek vir die bespreking van tekste oor verplasing of migrasie.

Waar migrasie na spesifiek Europa ter sprake is, is dit voorts van belang om daarop te let dat die woord Europa ook die implikasie dra van meer as net 'n fisiese of geografiese plek. Dit moet eerder beskou word as 'n kritiese hoek of perspektief op kulturele samestellings en veranderende kulturele hoedanighede. Bergfelder (2005: 320) maak in hierdie verband die volgende belangrike uitspraak - 'n stelling wat veral ook relevant is waar Kieślowski se posisionering in Europa ter sprake kom:

European is to understand it not so much as a stable cultural identity or category, but rather as an ongoing process, marked by indeterminacy or 'in-between-ness'. [...] Western culture is at its very roots, about experiences of spiritual dislocation and homelessness (sy kursivering).

Migrasie impliseer voorts ook die oorsteek van bepalende grense of drempels, hetsy in 'n letterlike of figuurlike sin. Hierdie grensoorskrydende handeling het meestal die belewing van verlies en leegheid en selfs angs tot gevolg. Indien een essensiële tema uitgesonder kan word waar tekste oor migrasie ter sprake kom, is dit juis dié van talle verliese wat ervaar word wanneer ' $n$ individu van sy geboorteland afskeid neem. Said (1984:159) staaf hierdie argument met sy stelling: "... true exile is a condition of terminal loss". Insiggewend in hierdie verband is die onderskeid wat Bernet (2005:635654) maak tussen heimwee en nostalgie - twee begrippe wat elk met die ervaring van verlies verband hou. Waar heimwee ter sprake is, is dit veral die ruimtelike dimensie van die gevoel, gemoedstoestand of stemming wat ter sprake kom. Daar is 'n sterk verlange na 'n plek van herkoms of ware tuiste, wat veral met die geboorteplek verband hou. Die verlange kan egter ook wees na die plek wat jy as jou ware bestemming beskou. Volgens die WAT dui nostalgie op 'n soms buitensporige verlange na 'n dikwels geromantiseerde of geïdealiseerde tydperk, toestand of omstandigheid in die verlede. Nostalgie moet volgens Bernet (2005:647) veral as 'n onmoontlike 
terugkeer begryp word, wat die onherroeplike verlies van die verlede insluit. Nostos is die Griekse woord vir terugkeer of aankoms, terwyl algos verband hou met pyn, leed of kommer.

\subsection{Kieślowski binne die raamwerk van migrasie}

Uit die voorafgaande bespreking is dit reeds duidelik dat die diskoers oor migrasie nie enkelvoudig is nie. Die ondersoek van Kieślowski se films en van hom as persoon en regisseur, word teen hierdie agtergrond uitgevoer. Kieślowski het homself nooit as volwaardige immigrant van die Weste beskou nie. Hy verduidelik byvoorbeeld in 'n onderhoud (Stok, 1995:1-2) dat hy homself nie 'n lewe sonder Pole kan voorstel nie, en dat hy dit baie moeilik vind om vir homself waarlik 'n plek in die Weste te vind ten spyte van die feit dat die omstandighede wonderlik is. As hy aan homself in die toekoms dink, kan hy homself slegs in Pole sien, en as hy weg is van Pole voel dit vir hom slegs maar vir 'n tydjie, asof hy in transito is. Die afleiding kan dus gemaak word dat Kieślowski se staat in Europa nie dié is van ballingskap, of selfs dié van volwaardige migrasie nie, maar eerder 'n dichotomie of 'n tussenintoestand, op die spanningslyn tussen plekke van die verlede én van die hede, naamlik Pole (die heimat, die plek van oorsprong) en Europa (die gasheerland, die plek van heenkome).

Die vraag ontstaan gevolglik in watter mate Kieślowski se persoonlike oorgang na die Weste, met die tradisioneel Westerse tradisies en kulturele norme, sowel as die kompleksiteit van sy tussentoestand of liminale staat, die temas en styl van die trilogie beïnvloed het. My tese is dat die tema van migrasie wel deeglik aan die regisseur, sowel as die films verbind kan word, maar hy hanteer dit op 'n indirekte en diskrete wyse, of by wyse van spreke, in die skadu van die oorkoepelende narratief.

\section{Sentrale temas in Three colours trilogy}

\subsection{Vryheid, gelykheid en broederskap}

Three colours trilogy neem die seminale idees van die Franse Rewolusie (vryheid, gelykheid en broederskap) as uitgangspunt, soos gesimboliseer in die kleure van die Franse vlag. Hierdie Franse (en by implikasie selfs Westerse) dictum staan in teenstelling met Pole waar sensuur en die manipulasie van waarheid en mag deur die regerende party aan die orde van die dag was. Kieślowski ondersoek egter ironies genoeg juis nié hierdie konsepte op politieke, sosiale of filosofiese vlak nie. Sy ondersoek geskied eer- 
der op menslike en die intiem persoonlike vlak, en hy fokus op die innerlike belewenisse van die karakters. Kieślowski ontgin die konsepte onder andere deur middel van die strategie inversie, ${ }^{3}$ want in al drie die films is daar by die hoofkarakters 'n strewe na, maar óók 'n negering van onderskeidelik die nosies van vryheid, gelykheid en broederskap. Laasgenoemde konsepte kan egter in 'n breër konteks ook in verband gebring word met migrasie. Vir die migrant wat hom-/haarself tussen twee wêrelde bevind waar begrippe soos vryheid/gevangenskap, hoort/vervreemding, gelykheid/ongelykheid en broederskap/isolasie voortdurend teenoor mekaar afspeel, is dit uiteraard juis problematiese aspekte op sosiale, politiese, sowel as persoonlike vlak.

Die tematiese stramien van Blue is enersyds die verwerking van 'n traumatiese ervaring van verlies, en andersyds die hantering van oënskynlike totale vryheid. $\mathrm{Na}$ haar gesin se dood is die hoofkarakter, Julie, sonder die beperkings van persoonlike bande, verantwoordelikhede of finansiële verpligtinge, maar ten spyte daarvan is sy nié vry nie, en wil sy onderliggend ook nie onvoorwaardelik vry wees nie. Hoewel sy dus oënskynlike totale vryheid beleef, is sy op geestelike vlak 'n gevangene van haar volgehoue smart, haar pynigende verlies en veral van haar folterende herinneringe. In aansluiting by die blou kleur van die Franse vlag, handel die film dus tematies oor vryheid, maar insgelyks word die onvolmaaktheid van menslike vryheid terselfdertyd beklemtoon.

In White, die tweede film van die trilogie, kan vernedering en ongelykheid as sentrale temas voorgehou word, dus weereens die teenpool van gelykheid. Ongelyke verhoudings balanseer in hierdie narratief op geestelike, sosiale, politieke en kulturele vlak. Karol, die protagonis, bevind hom as Poolse migrant in Frankryk in 'n ernstige posisie van ongelykheid. Hy ervaar nie alleen die verlies van sy vaderland nie, maar aan die begin van die film verloor hy die liefde van sy vrou omdat hy nie die huwelik kan voltrek nie, en gevolglik verloor hy ook sy huwelikstatus en skamele aardse besittings. Op simboliese vlak is daar ook die verlies van sy manlike ego vanweë sy seksuele onvermoë. Die film ontgin op komiese wyse die ommekeer van rolle: vir Karol die opheffing van ongelykheid en 'n herwinning van die magsbalans ten koste van sy vrou. Die slotsom

3 "Verwant aan die spieël-simbool (wat regs lyk, is links en omgekeerd) dui die inversie-simbool op die omkering, maar ook saambestaan van opponerende wêrelde: jin/jang, droom/werklikheid, wit/swart" (Weideman, 2006:8). 
van die film kommunikeer uiteindelik op paradoksale wyse dat die mens nie werklik gelyk kán wees, of waarlik gelyk wíl wees nie. White gaan dus oor gelykheid, verstaan as 'n oënskynlike kontradiksie. In 'n Westerse denkraamwerk word die konsep van "gelykheid" verstaan dat almal gelyk wil wees. Kieślowski (Stok, 1995:217) is egter self ook van mening dat niemand regtig gelyk wil wees nie. Hy verwys in hierdie verband na 'n gesegde in Pole: daar is diegene wat gelyk is en daar is diegene wat meer gelyk is. Hierdie gesegde is gedurende die Kommunisme gebruik en dit word waarskynlik nog steeds gebruik.

Tematies handel die derde film van die trilogie, Red, oor isolasie. Die karakters beleef hul onderskeie wêrelde as eensaam en gefragmenteerd en bevind hulle in gebroke verhoudings. Joseph Kern, die regter, se koue sinisme, sy doelbewuste passiewe en geïsoleerde bestaan, en sy gebrek aan empatie beklemtoon verder die gebrek aan broederskap wat die film kommunikeer. Kieślowski (Stok, 1995: 17) se opvattings in hierdie verband is weereens insiggewend. Hy is van mening dat al waarvoor ons regtig omgee, onsself is. Selfs wanneer ons aandag skenk aan ander mense, dink ons steeds aan onsself. Een van die temas wat Rooi kommunikeer, is broederskap. Die vraag ontstaan egter of wanneer ons van onsself gee, ons dit nie doen omdat ons 'n beter opinie van onsself wil hê nie?

\subsection{Migrasie as tema}

Die uitgangspunt van hierdie artikel is dat die tema van migrasie (hetsy migrasie as letterlike handeling, of migrasie as modus van die verbeelding) aan die trilogie verbind kan word. Aspekte van verplasing soos oorgangsprosesse, marginalisering en isolasie kom gevolglik ook ter sprake. Hierdie tema kan boonop ook as liminaal beskou word, omdat daar by implikasie 'n drempel tussen die konkrete of reële ervaring en die simboliese of metafisiese ervaring ingebed is. Die hoofkarakters in al drie die films bevind hulself in transito tussen twee wêrelde, hetsy 'n konkrete of 'n verbeelde wêreld. Geoff Andrew (1998:69) se argument ten opsigte van al drie die narratiewe kan ter stawing aangehaal word:

The narratives, too, can seem mysterious, not only because of their elliptical construction, which allows the audience to piece them together only gradually, but because they are filled with odd coincidences, repetitions, parallels and connections. The topography of the immaterial and abstract - whether it be the individual soul, or the workings of destiny and chance - is ex- 
plored, as it were, in the spaces that exist between images (sy kursivering).

Verblyf en verplasing, die reis en die proses van op reis gaan, sowel as die kwessie van die oorsteek van grense, is uit die aard van die saak sleutelaspekte wanneer die kwessie van migrasie in die films ter sprake kom. Vir die migrant neem die reis talle moontlike vorme aan en daar word in die proses verskillende grense oorgesteek, nie slegs fisies en geografies nie, maar ook psigiese, metaforiese, sosiale en kulturele grense. Naficy (2001) bespreek in sy boek 'n aantal aspekte van vreemdelingskap en diaspora wat 'n interessante lig werp op die trilogie, en terselfdertyd die (soms implisiete) tema van migrasie in die films bevestig. Hy maak onder andere die relevante stelling dat grensruimtes van ballingskap en grensoorgange nie slegs ingeskryf is in vaste oorgangsterreine soos lughawens, seehawens, tonnels, hotelle en motelle nie, maar ook in mobiele ruimtes soos voertuie en tasse. Voertuie voorsien nie slegs empiriese leidrade na geografiese plekke en sosiale groeperings nie, maar is ook metaforiese omwerkings van die nosies van reis, terugkeer en identiteit. Dit is insiggewend om in dié verband op die onderskeie openingstonele van die films te let.

Die openingsekwens van Blue toon 'n abstrakte beeld van 'n swart doek met grys vertikale lyne wat stadig op die skerm verskyn. Dit is eers die klank van 'n toeter wat die kyker tot die besef bring dat die beeld dié is van 'n motor wat op 'n besige snelweg ry. Na 'n vlugtige verposing hervat die gesin in die voertuig die reis, maar dit eindig sekondes later traumaties in 'n tragiese motorongeluk. Vir Julie is dit terselfdertyd ook dié bepalende drempelervaring, want daar is sprake van 'n transgressie van psigologiese, sowel as metaforiese grense, soos later in hierdie betoog uitgewys sal word.

In White toon die openingsekwens 'n groot tas wat op 'n vervoerband in 'n lughawe beweeg. Die tas, die moontlike inhoud en die versweë konteks prikkel onmiddellik die kyker se nuuskierigheid en skep verwagting. Hierdie sekwens is 'n prolepsis wat verwys na 'n gebeurtenis wat later in die film vollediger herhaal word as Karol letterlik sy geboorteland ingesmokkel word. Die tas is ook in hierdie verband onteenseglik ' $n$ indeksale teken na reis en migrasie. Boonop stel die tas as metafoor sowel die vaste konstruksie as die mobiliteit van identiteit voor.

Die openingskote van die derde film in die trilogie, Red, fokus op 'n telefoon met daarnaas 'n glas en Valentine se foto. Daarna volg die kamera met 'n hoëspoedsekwensie die elektroniese impuls van die 
oproep deur die telefoonkabels totdat die foon aan die ander kant van die water begin lui. Die telefoon, telefoongesprekke, gemiste telefoonoproepe en afgeluisterde oproepe volg soos 'n goue draad deur die narratief. Die telefoon word in hierdie film in die eerste plek onmiskenbaar die metafoor vir kommunikasie en wankommunikasie, broederskap en isolasie waaroor dit in die verhaal gaan. Vir Naficy $(2001: 101)$ is die telefoon egter in die tweede plek ' $n$ epistel wat alles te make het met verplasing en verlies. Hy verduidelik soos volg:

Exile and epistolarity are constitutively linked because both are driven by distance, separation, absence, and loss and by the desire to bridge the multiple gaps. Whatever form the epistle takes, whether a letter, a note scribbled on a napkin, a telephone conversation, a video, or an e-mail message, it becomes, a metonymic and a metaphoric displacement of desire the desire to be with an other and to reimagine an elsewhere and other times (kursivering - AN).

Samevattend is dit dus duidelik dat al drie films se insette besliste leidrade verstrek aan die tema van migrasie, hetsy op letterlike, metaforiese of verbeeldingsvlak.

\section{Three colours trilogy en die poëtika van verlies}

\subsection{Poëtika van verlies en afwesigheid}

Naas die intens persoonlike ervaring wat migrasie kenmerk, is dit ook 'n kollektiewe drempelervaring. Die emigrant het geen keuse nie as om die drempel van die bekende na die onbekende oor te steek - 'n voor en daarna in terme van persoonlike, sosiale en kulturele ruimtes. Daar is dus sprake van die oorsteek van 'n bepalende grens sodat die emigrant hom/haar (letterlik) in die ruimte van die Ander bevind. In aansluiting by Naficy se aangehaalde uitspraak, bied Smith (2004:43) se opvatting oor die gevolge van die oorsteek van 'n drempel vervolgens 'n bruikbare raamwerk waarvolgens gevolge van die drempelervaring in Three colours uitgelig kan word. Volgens Smith (2004:43) word die transgressie van een staat na die volgende gekenmerk deur onsekerheid, en is dit 'n abjekte ruimtelike oomblik waarin ons nie weet of ons dit moet inkorporeer of verban nie. Dit is 'n oomblik van verlies van alles wat voorafgegaan het, van die afwesigheid van sowel vantevore as later, van angs wat gegeneer word deur die verlies en onsekerheid en van begeerte as gevolg van die gemis wat ontstaan het. 
Smith (2004:44) gebruik die term Nachträchlichkeit in navolging van Freud om in retrospek sin te maak van 'n vroeëre disparate gebeurtenis. Hierdie proses gaan gewoonlik ook gepaard met angs. Die angs kan ontstaan as gevolg van die oorsteek van die drempel, maar ook as gevolg van die (mislukte) poging om die verlies te erken en te verwerk. Vrees vir die Ander, die anderkant, die andersheid kan egter ook aanleiding gee vir die angs wat ervaar word. Ook Sibley (1995:33) benadruk die liminale sone as 'n ruimte van onsekerheid en diskontinuïteit, en gevolglik as 'n bron van angs. Volgens hom is dit 'n sone van abjeksie, wat geëlimineer behoort te word ten einde angs te verminder, maar omdat die individu dikwels geen beheer het oor die verloop van sake nie, is dit 'n saak van onmoontlikheid. Smith (2004:44) wys voorts daarop dat daar in die proses van Nachträchlichkeit twee moontlike strategieë aangewend kan word: in die eerste plek kan die persoon weier om die naderende staat van verlies te erken, want deur dié erkenning word hy/sy gedwing om te rou oor die verlies. In plaas daarvan onttrek die persoon in 'n staat van melancholie en klou vas aan iets wat besig is om te verdwyn en wat binnekort nie langer daar gaan wees nie. In die tweede plek kan die gebeurtenis, die drempel self, as 'n afleiding gebruik word om die afgryslikheid van die leegheid daaragter te blokkeer. Die vraag ontstaan dus op watter wyse Kieślowski se Trilogie die liminale ruimte van verlies, afwesigheid, angs en begeerte artikuleer. Daar word vervolgens op enkele van hierdie aspekte gefokus.

Oorkoepelend staan al drie die films duidelik in die teken van verlies en afwesigheid. Die oorheersende tema van verlies spruit kollektief uit die oorsteek van bepalende grense van die protagoniste van die onderskeidelike narratiewe, na 'n liminale ruimte van gemis, verlies en angs. Daar is dus sprake van elemente van die genre van die tragiese, wat beskryf kan word in terme van 'n oorgangsrite vanaf katastrofe na katarsis.

\subsection{Three colours trilogy: Blue}

Aansluitend by die tema van migrasie word daar in die eerste film van die trilogie gefokus op die bykomende tema van verlies. Die beslissende drempelervaring in hierdie geval is die motorongeluk waarin Julie haar eggenoot en kind verloor. Julie se verlies word egter vermenigvuldig as sy uitvind van haar man se verraad en sy liefde vir sy swanger minnares. Op psigiese vlak is daar dus ook die verlies van ' $n$ persoonlike en gedeelde geskiedenis in huweliksverband. Daar is gevolglik 'n letterlike, sowel as emosionele verbrok- 
keling van haar vertroude en gekoesterde wêreld, haar geestelike en emosionele "tuisland", en gepaardgaande dus ook 'n verlies van 'n persoonlik gekonstrueerde identiteit.

Die stelling kan myns insiens ook gemaak word dat Julie haarself op simboliese vlak tussen twee sterftes bevind. Sy verkeer in 'n toestand van 'n geestelike dood, terwyl sy haar in die werklikheid tussen lewendes bevind (anders byvoorbeeld as die karakters in Sixth sense wat dood is, maar nie weet dat hulle dood is nie). Ironies genoeg is Julie se enigste band met die verlede haar ma. Dit beklemtoon egter juis Julie se verlies van 'n gedeelte persoonlike geskiedenis, want haar ma bevind haar óók in die liminale staat tussen lewe en dood. Sy is fisies lewend maar identiteitloos, want as gevolg van haar geheueverlies is sy intellektueel en psigies dood. Žižek (2001:264) bevestig bogenoemde stelling met die volgende belangrike argument:

The Colours trilogy introduces a new element in this choice between life and interpellation, a third term, the 'zero-level' of utter contraction/selfwithdrawal, of symbolic death, which is neither mission nor life, but their obscure ground, their 'vanishing mediator'. Each part of the trilogy focuses on the voyage from a certain mode of radical self-withdrawal to the acceptance of others, the reintegration into the social universe.

Julie se toestand toon kenmerke van die ervaring van migrasie: daar is verplasing en verstrooiing van die oorspronklike sentrum (haar huwelik en gesinslewe). Sy onttrek haar boonop doelbewus van alle konkrete manifestasies van haar lewe voor die ongeluk. Sy verkoop haar huis en besittings, verbreek alle verhoudings en verplaas haarself na 'n onpersoonlike woonplek in die stad waar sy poog om as vreemdeling anoniem te vertoef. Die feit dat sy die huis, sowel as die inhoud daarvan verkoop, is nie alleen 'n konkrete handeling nie, maar dit is óók ' $n$ belangrike simboliese gebaar. Die huis is by uitstek die plek wat persoonlike ruimte beset en die essensie van 'n mens se bestaan definieer. Ook vir die migrant is die huis 'n betekenisvolle ruimte. Die bewoner wat die huis moet verlaat om na 'n ander ruimte verplaas te word, word baie spesifiek steeds deur herinneringe aan die huis verbind. Bachelard (1994:4-5) se bekende opvattings oor die huis en geborgenheid is ook relevant en van toepassing op Blue. Herinnering is vir Bachelard die metaforiese en dus poëtiese weergawe van 'n mens se verlede, en in hierdie herinneringe koester 'n mens die geluk van die verlede of rekonstrueer ' $n$ mens die verlede tot fiksionele drome van geluk. 
In die lig van Bachelard se opvatting is Julie se verkoop van die huis dus 'n doelbewuste aflegging van haar verlede, haar drome van geluk, haar herinneringe en persoonlike geskiedenis; 'n aflegging dus van die essensie van haar identiteit en bestaan. Hierdie handeling stem ooreen met die migrant se tydelike aanneming van 'n plek van heenkome in 'n nuwe tuisland. Sy bevind haar dus in die tipiese tussentoestand van die drempelervaring. Smith (2004:44) se opvatting in hierdie verband kan weereens van toepassing gemaak word: ten einde te ontken wat aan die ander kant van die drempel lê, word die drempel met ongelyke en buitensporige betekenis gelaai. Die drempel verberg sodoende die leegheid wat daaragter lê.

Die strategie van ontkenning en die drempelfiksasie in 'n poging om die angs daardeur (tydelik) te besweer, manifesteer onder andere deur die presentasie van spoke of spookbeelde. Die spookbeeld verteenwoordig volgens Smith (2004:45) die idee van iets wat is, maar ook nie meer daar is nie; iets wat weg is, maar steeds bly omdat dit gesien en/of gehoor kan word. So 'n spookbeeld kan gevolglik beskou word as die verteenwoordiging van 'n melancholiese staat. In Blue is die vergestalting van die verlies visueel sowel as ouditief. Die musiek in die film is ekstra-diëgeties en dit verteenwoordig vir Julie die folterende spookbeelde van die verlede. Veelseggend is die feit dat die musieksekwense telkens met 'n oorheersende blou doek in verband gebring word. Die kleur blou word dus visueel tekenend van die verlies en leegheid wat Julie ervaar en is inderdaad tekenend van haar melancholiese staat. Die spookbeeld kan voorts ook 'n afbeelding wees van die ander/Ander, sowel buite as binne die subjek self. Die musiek word in Julie se geval 'n verbeelding van marteling sowel as ontworteling, want dit is inherent deel van haarself, sowel as van die ontslape eggenoot en die band wat hulle gedeel het. Hierdie musiek is ironies uiteindelik ook die middel waardeur Julie gedwing word om uit die staat van melancholie en drempelfiksasie te beweeg na ' $n$ proses van rou en loslating. Julie word deur Olivier gedwing om die concerto te voltooi. Ook hierdie concerto vir die eenheid van Europa moet myns insiens op metaforiese vlak, eerder as alleen op konkrete vlak gelees word. Die onvoltooide concerto dien onder andere óók as metafoor vir Julie se liminale geestestoestand en haar onvervuldheid. $\mathrm{Na}$ die voltooiing van die concerto suggereer die slotsekwense van die film Julie se finale deurbreking van die stagnante drempeltoestand. Die finale sekwens begin met 'n swart doek waarna fragmente van beelde van die verskillende karakters in die verhaal vertoon word beelde wat getuig van "sluiting". Die laaste beeld op die skerm is dié van Julie wat deur 'n venster kyk terwyl daar 'n traan oor haar wang 
loop - 'n bewys van haar uiteindelike oorgang na 'n postliminale staat waarin sy in staat is om volledig te rou. Dit is insiggewend dat ook White, sowel as Red, eindig met die beelde van onderskeidelik Karol en Kern wat in die slotsekwens tot trane gedwing word. Ook vir hierdie karakters is dit dus uiteindelik moontlik om die individuele rouproses te volvoer.

Olivier se aandrang dat Julie die concerto voltooi, én die erkenning daarvoor aanvaar, impliseer dat Julie ten slotte op hierdie wyse gedwing word om haar begeerte(s) te erken, te herstel en te reapproprieer, hoe pynlik dit ook mag wees. Žižek (2001:160) se siening kan in hierdie verband ter stawing aangehaal word: "Desire is thus literally realised - not 'fulfilled', but actualized, rendered visible, as desire" (sy kursivering). Hierdie begeertes kan onder andere gesien word as die begeerte om werklik te rou oor haar verlies, asook 'n begeerte tot versoening en tot heling van haar gebroke wêreld. Die suggestie is dus dat sy ten slotte reis vanuit 'n landskap van donkerte en leegheid na 'n wêreld van agape, wat die moontlikheid insluit dat sy uiteindelik weer in staat sal wees om 'n nuwe liefdesverhouding aan te gaan. Sy aanvaar dus die uitdaging om die rouproses te volvoer ten einde weer voluit te leef.

\subsection{Three colours trilogy: White}

Die ooglopende raam waarin Kieślowski sy narratief in White konstrueer, is die teks van 'n letterlike én 'n metaforiese ontheemding. Karol bevind hom aan die begin van die verhaal as Poolse immigrant in Frankryk in 'n oorheersende posisie van verlies: in dié limbo is hy stemloos, magteloos en 'n sosiale verstoteling. Soos reeds genoem, beleef hy op akute wyse die verlies van sy vaderland. As gevolg van sy materiële en seksuele mislukkings word hy verder gestroop van sy materiële besittings, sy huwelik en die liefde van sy vrou, maar bowenal van sy menswaardigheid en selfvertroue. Kickazola (2004:280) argumenteer dat die film nie verstaan moet word as 'n realistiese mimetiese narratief nie, maar as 'n karikatuuragtige satire op kontemporêre materialisme en die verlies van tradisionele waardes. Hy redeneer voorts dat Kieślowski ook in dialoog tree met sy vorige werke, omdat hy retrospektief 'n nostalgiese blik werp op die dramatiese omwentelings in sy vaderland. Ten spyte van Kieślowski se verwerping van politieke onderwerpe in sy laaste films, herbesoek hy dus tog weer dié onderwerp, maar op 'n spottende, komiese wyse. Die blik van die migrant (hoe tydelik ook al) op sy agtergelate tuisland is myns insiens dus duidelik ook ter sprake. 
Karol se impotensie in sy nuwe vaderland is by uitstek 'n metafoor van sy gevoel van minderwaardigheid en ontheemding, sowel as sy gebrek aan mag vanweë sy marginale posisie. In terme van Smith se raamwerk is daar by Karol ook sprake van 'n drempelfiksasie. Anders as Julie wat in 'n toestand van verstarring verkeer, wend Karol hom tot woedende wraak. As hy na sy vaderland terugkeer, neem hy (oënskynlik) beheer van sy eie lewe en werk vir spoedige materiële welvaart. Sy melancholiese staat word egter óók (soos in Blue) weerspieël in die spookbeeld van die vrou wat hom verneder het. Clewell (2000) se opmerking oor die spookbeeld en verlies is in hierdie verband tersaaklik:

Haunted throughout the film by a white image of Dominique's face at their wedding, clearly a recurring flashback of nostalgic fullness, Karol stages his death, deceives his ex-wife into attending the funeral, and presides as hidden director over his grave. Displacing his own loss onto a woman, Karol overdetermines the bereavement of lost love as a strategy to empower the male ego with autonomy and omnipotence uncorroborated by social forms of life.

Die rolle is ten slotte omgekeer as hy sy voormalige vrou onder valse voorwendsels na Pole laat kom. As voyeur verlustig hy hom in Dominique se trane tydens sy begrafnis, en herwin selfs sy viriliteit, omdat hy hom in 'n herwonne magsposisie bevind. Hy verras sy vrou in die hotel na die begrafnis en is selfs weer in staat tot die volledige liefdesspel. Die paar is egter in die slotsekwens steeds geskei, hoewel haar gebaretaal vanuit die venster van die tronk kan getuig van haar moontlike hernude liefde en trou.

Soos in Blue, eindig die film met trane in Karol se oë. Binne die raamwerk van die poëtika van verlies en begeerte, kan die slot dus ook geïnterpreteer word dat Karol (soos Julie) nou eers in staat is om die werklike verlies te rekonsilieer, en dus oor te gaan na 'n postliminale staat van rou en geestelike reïntegrasie, wat 'n staat van volledige selfvervulling en selfgelding in die vooruitsig stel. Ook hier is myns insiens sprake van die besef of verwerkliking, eerder as die voltrekking van begeerte, naamlik die begeerte na 'n egte geestelike hereniging en voltrekking van sy huwelik, gebaseer op wedersydse respek en menswaardigheid.

\subsection{Three colours trilogy: Red}

Die tema van verlies manifesteer minder akuut in Red as in die vorige twee films, en geskied eerder op abstrakte en geestelike as konkrete vlak. Anders as die jeugdige Julie en Karol, bevind Kern 
hom as bejaarde nader aan die einde van 'n lewe. Benewens die verraad en verlies van 'n geliefde vrou in sy jeug, is daar dus gepaardgaande met die ouderdom die onvermydelike verlies van sy jeug en van verlore of verspeelde geleenthede. Sy lewe is ooglopend gebroke en onvervuld. Bowenal is daar ironies ook die verlies van die vermoë om sinvol met sy medemens te kommunikeer. Hy bevind homself (soos Julie) in die liminale staat tussen twee sterftes. Die huis as betekenisvolle ruimte (soos in Blue) is hier ook besonder relevant. Valentine sowel as die kyker se eerste ontmoeting met Kern sien soos volg daar uit: uit die toestand van die huis en die verlate kamers kom dit voor asof hy alreeds dekades lank daar sit. Die verwronge klanke van die radio suggereer selfs dat hy moontlik dood is (en in 'n sekere sin is hy inderdaad - gesuspendeer in die halwe lewe van isolasie en eenrigtingkommunikasie). Die essensie van Kern se bestaan word met ander woorde op hierdie wyse reeds ruimtelik gedefinieer.

Soos by Julie, is hier ook sprake van 'n selfopgelegde gevangenskap en isolasie wat hom in staat stel om sy medemens deur middel van sy voyeurisme en afluisterapparate te sien en te hoor, maar nie aan te raak nie. Sy toestand is dus by uitstek dié van melancholiese ontkenning en 'n onttrekking van die bewussyn. Vir die regter het die tyd tot stilstand gekom. Dit is, ironies genoeg, die stille kommunikasie tussen die verbitterde regter en die goedhartige Valentine wat hom uit sy toestand van gestagneerde isolasie laat beweeg na 'n postliminale staat waar hy weer in staat is om volledig uit te reik na sy medemens.

Die slottonele van Red verreken sowel die tema van migrasie as die poëtika van verlies, en bind die trilogie finaal tot 'n eenheid. Die tema van reis en die oorsteek van grense wat met migrasie verband hou, word in die slottonele van Red beklemtoon. Aan die begin van hierdie artikel is aangevoer dat die onderskeie sentrale karakters hulself in transito tussen twee wêrelde bevind. Hierdie metafisiese/ simboliese reise word ten slotte konkreet vergestalt as die kamera fokus op die veerboot wat in die proses is om die kanaal oor te steek. Naficy (2001:222-223) wys in sy betoog oor die nosie van reis ten opsigte van migrasie dat daar met betrekking tot elke reis sprake is van sowel rigting as duur; reise transformeer dus ruimte in tyd. In terme van rigting is daar drie soorte reise wat op die banneling of migrant betrekking het, wat onderskei kan word. In die eerste plek is daar konkrete reise van ontsnapping en van die soeke en vind van 'n eie tuiste. In die tweede plek is daar dié reise wat getuig van soeke sonder 'n eindbestemming, van haweloosheid en verlore- 
wees. Ten slotte is daar innerlike reise van die terugkeer na die tuiste of tuisland. Dit is veral laasgenoemde wat betrekking het op die trilogie. Daar is slegs sewe oorlewendes van die rampspoedige veerbootongeluk, insluitend Julie (Blue), Karol en Dominique (White), Olivier (Blue), sowel as Valentine en Auguste (Red) wat veilig aan land gebring word. Indien hierdie uitkoms aan die poëtika van verlies verbind word, bevestig dit die afleidings wat vroeër in hierdie betoog gemaak is, naamlik dat die onderskeie protagoniste van die verhale vanuit die liminale staat van verlies en afwesigheid en begeerte beweeg het na 'n veilige postliminale staat, waar die rouproses volledig voltooi kan word en die helingsproses 'n aanvang kan neem. Dit is ook in hierdie lig wat die slotsekwens gelees kan word: die beeld van die regter wat deur die gebreekte ruit van sy huis staar terwyl hy vir die eerste keer in staat is om te huil. Die gebreekte ruit sinjaleer waarskynlik op metaforiese vlak ook dat die skeiding tussen die regter en die res van die wêreld finaal opgehef is. Die persona van die regter word egter óók deur sommige kritici aan Kieślowski self verbind. Die slotsekwens kan dus ook geïnterpreteer word dat die regisseur as artistieke dirigent vanaf 'n afstand na sy karakters kyk en afskeid neem. In 'n breër verband kan Kieślowski as persoon inderdaad by die slottoneel betrek word, want hy het met die voltooiing van die trilogie sy uittrede aangekondig en na Pole teruggekeer. Die staat van migrasie is dus op letterlike, sowel as psigiese vlak opgehef.

\section{Ten slotte}

Met hierdie ondersoek is breedweg nagegaan hoe verbandhoudende sake onder die sambreelterm migrasie ingesluit word. Migrasie kan op letterlike vlak 'n oorsteek van (lands)grense impliseer, én op figuurlike vlak dui op 'n (post)moderne kondisie, 'n modus van die verbeelding, sowel as 'n metaforiese verwysing. Kieślowski se Three colours trilogy pas geredelik binne hierdie raamwerk. Ponzanesi en Merolla (2005:6) se stelling oor die ervaring van migrasie kan opsommend aangehaal word:

The experience of migration, of what it means to be a migrant in-between spaces, identifications, and forms of expression becomes lionized as the new existential condition that is based on the re-sitting of imposed boundaries, undermining of codified cultural outings, and negotiation of multiple sites of differentiations.

Die tese dat die tema van migrasie wel deeglik aan die regisseur, sowel as die films verbind kan word, is as geldig bewys. In die loop 
van die bespreking het dit voorts ook geblyk dat sowel die artistieke ekspressie, as die styl van die films deeglik daardeur beïnvloed is. Verlies en die hantering van verlies, as uitvloeisel van die grensoorskrydende handeling van migrasie, is ' $n$ gegewe in die trilogie. Elke protagonis probeer op 'n persoonlike manier die ervaring van verlies verwerk: Julie in Blue deur 'n drempelfiksasie, Karol in White deur woedende wraak en Kern in Red deur die strategie van ontkenning.

\section{Geraadpleegde bronne}

ANDREW, G. 1998. The Three colours trilogy. London: British Film Institute. BACHELARD. G. 1994. The poetics of space. Boston: Beacon.

BERGFELDER, T. 2005. National, transnational or supernational cinema? Rethinking European film studies. Media, culture \& society, 27(3):315-331. BERNET, R. 2005. Heimwee en nostalgie. Tijdschrift voor filosofie, 67:635-654.

BRAH, A. 1996. Cartographies of diaspora: contesting identities. London: Routledge.

CASTLES, S. \& MILLER, M.J. 1998. The age of migration: international population movements in the modern world. Houndmills: Palgrave.

CHAMBERS, I. 1994. Migrancy, culture, identity. London: Routledge.

CLEWELL, T. 2000. The shades of modern mourning in Three colours trilogy. Literature Film Quarterly. http://www.findarticles.com/p/articles/mi_qa3/68/ is 00001/af n889/015 Date of access: 4 Jun. 2007.

HANNERZ, U. 2000 . Transnational connections: culture, people, places. London: Routledge.

HAT

kyk Odendal

HAUPTFLEISCH, D.C. 1991. Woordeboek van die Afrikaanse Taal. Deel 8. Stellenbosch: Buro van die WAT.

KEARNEY, R. 1988. Transitions: narratives in modern Irish culture. Dublin: Wolfhound.

KICKAZOLA, J.G. 2004. The films of Krzysztof Kieślowski: the liminal image. New York: Continuum.

NAFICY, H. 2001. An accented cinema: exilic and diasporic filmmaking. Princeton: Princeton University Press.

NEERFOORT, H. 2006. Migrasie is die goudmyn én valkuil van Afrikaanse literatuur. Die Burger: 9, 23 Jan.

ODENDAL, F.F., red. 1994. Verklarende Handwoordeboek van die Afrikaanse Taal. Johannesburg: Perskor.

PETERS, J.D. 1999. Exile, nomadism, and diaspora: the stakes of mobility in the Western canon. (In Naficy, H. Home, exile, homeland: film, media, and the politics of place. New York: Routledge. p. 17-44.)

PONZANESI, S. \& MEROLLA, D. 2005. Migrant cartographies: new cultural and literary spaces in post-colonial Europe. Oxford: Lexington.

RUSHDIE, S. 1991. Imaginary homelands: essays and criticism 1981-1991. London: Granta Books.

SAFRAN, W. 1991. Diasporas in modern societies: myths of homeland and return. Diaspora, 1(1):83-99.

SAID, E.W. 1984. Reflections on exile and other essays. Cambridge: Harvard University Press. 
SIBLEY, D. 1995. Geographies of exclusion: society and difference in the West. London: Routledge.

SMITH, K. 2004. The emptiness of zero, representations of loss, absence, anxiety and desire in the late twentieth century. Critical quarterly, 26(1):4059.

STOK, D. 1995. Kieślowski on Kieślowski. London: Faber \& Faber.

WAT

kyk HAUPTFLEISCH

WEIDEMAN, G. 2006. Die clowneske in die kortverhale van Abraham H. de Vries. Deel 1: 'n Inleidende verkenning. Stilet, 18(2):1-21.

ŽlŽEK, S. 2001. The fright of real tears: Krzysztof Kieślowski between theory and post-theory. London: BFI.

\section{Kernbegrippe:}

Kieślowski, Krzysztof

migrasie

poëtika van verlies

Three colours trilogy: Blue, White, Red

Key concepts:

Kieślowski, Krzysztof

migration

poetics of loss

Three colours trilogy: Blue, White, Red 